in Fettseifen und Glycerin verwandelt werden, welche in Wasser löslich auf dem Wege der Diffusion in das Epithelprotoplasma eindringen, um daselbst aufs Neue als Fettregeneratoren zu dienen.

Ausfiuhrliches iiber die Versuche mitzutheilen behalte ich mir noch vor. -

(Aus dem physiologischen Institut der Universität Strassburg.)

\title{
Eine neue Methode den Druck in der Lunge zu messen.
}

Von

\section{Jul. Rich. Ewald.}

\section{Vorlänfige Mittheilung.}

Zahlreiche Versuche, die ich ïber den Druck forcirter Athembewegungen an Menschen und Thieren anstellte, gaben mir die Ueberzeugung, dass die bis jetzt angewandte Methode, direct in ein Manometer athmen zu lassen, eine sehr unsichere ist. Die Wirkung der Mundmuskulatur ist eben wegen ihrer hohen positiven und negativen Druckhöhen, die sie hervorbringen kann, äusserst störend. So können beispielsweise viele Mensehen durch Saugen einen negativen Druck von $700 \mathrm{~mm} \mathrm{Hg}$ und mehr erzeugen, und es braucht sich daher mit der Athembewegung nur eine geringe Saugbewegung zu combiniren, um das Resultat wesentlich zu ändern. Mögen nun auch einzelne Menschen Bewegungen der Mundmuskulatur bei forcirtom Athmen ganz vermeiden können, so sind dies doch nur immer vereinzelte Fälle, und diese waren unter den anderen bis jetzt nicht herauszufinden, da es kein Mittel gab, um za constatiren ob der Druck allein in der Lunge oder auch theilweise im Mnnde erzengt wurde. Man suchte ans der Höhe des Druckes und aus seinen grösseren oder kleineren Schwankungen sich ein Urtheil darüber zu bilden; aber es gestatten hier nur die Extreme einen einigermaassen sicheren Schluss. 
Es gelang mir nun eine ganz sichere und dabei sehr einfache Methode, die Mundmuskulatur völlig auszuschliessen., zu finden. Man braucht nämlich nur, während man in das betreffende Manometer hinein athmet, gleichzeitig einen Ton im Kehlkopf zu erzengen, also hineinzusingen. So lange man noch im Stande ist einen Ton zu erzeugen, ist auch ganz sicher unterhalb der Glottis noch ein grösserer Druck als oberhalb derselben in der Mundhöhle und dem Manometer. Da nun das Quantum Luft, das nöthig ist, um uiberhaupt noch einen Ton erzengen zu können, ein ganz ausserordentlich kleines ist, so wird schliesslich, wenn man nicht mehr im Stande ist einen Ton hervorzubringen, der Druck in der Lunge von dem Druck oberhalb der Glottis im Manometer nur um ein verschwindend Kleines verschieden sein. Liest man also den Druck am Manometer ab sobald der Ton abbricht, so hat man den gewünschten Lungendruck. Genau das Gleiche findet bei der Einathmung statt, nur dass es sich um negativen Druck handelt.

In beiden Fällen kann man nun, nachdem man ausser Stande ist, noch einen Ton zu erzengen, den Ausschlag am Manometer noch bedeutend vergrössern - das ist eben die Wirkung der Mundmuskulatur.

Eine andere Verbesserung, die mir sehr willkommene Dienste geleistet hat, ist die Einschaltung eines Ventils zwischen Mund und Manometer, eine Idee, die ich Herrn Prof. Goltz verdanke. Hierdurch verbindet man folgende Vortheile: 1) Die betreffende Person, deren Lungendruck bestimmt werden soll, kann um neuen Athem zu holen, den Versuch . beliebig oft unterbrechen. 2) Die Eigenschwingungen des Quecksilbers lassen sich ganz vermeiden, indem man von einer gewissen Höhe desselben an von Millimeter zu Millimeter weiter pressen lässt. 3) Man kann genau und bequem das Resultat am Manometer ablesen. Es wurde mir aber nicht leicht ein geeignetes Ventil zu finden, das bei schnellem und luftdichtem Verschluss einen grossen Druck ertragen konnte und sich doch dabei durch einen möglichst kleinen Ueberdruck öffnete. Nach langem Probiren erwies sich als dazu recht geeignet ein Blasenventil mit einer besonderen Sicherung für grosse Druckdifferenzen, die die dünne Blase sonst gesprengt hätten.

Indem ich zwei solche Ventile, von denen das eine mit dem Manometer, das andere mit der äusseren Luft communicirte, beim Experiment mit Thieren anwandte, war es möglich den stärksten 
Exspirationsdruck bei zugleich grösster Füllung der Lungen und den stärksten Inspirationsdruck bei zugleich geringster Füllung derselben zu messen. $\mathrm{Zu}$ diesen Versuchen wurde eine grössere Zahl von Hunden und Kaninchen tracheotomirt, was auf das forcirte A th men keinen nachtheiligen Einfluss haben kann, wenn man dies anch nicht in gleicher Weise von der normalen Athmung behaupten darf. Letzteres ist häufig, auch wenn von der meist gesteigerten Frequenz der Athemzüge abgesehen werden soll, schon allein dem Athemgeräusch zu entnehmen. Den genaueren Beweis liefert die Athemdruckeurve. Ich bin leider gezwungen diese Versuchsreihen, die wohl ein gewisses Interesse in Anspruch nehmen können, zu unterbrechen, werde sie aber sobald sie zum Abschluss gekommen sind publiciren.

(Aus dem physikalischen Seminar zu Rostock.)

\title{
Mathematische Theorie der Periscopie des menschlichen Auges.
}

\author{
Von \\ W. Rasmus und A. Waner.
}

(Hierzu Taf. I.)

Für das menschliche Auge beträgt nach den Messungen von Förster, Landolt, Uschak off, Reich und Aubert ${ }^{1}$ ) das Gesichtsfeld in horizontaler Ausdehnung gegen $150^{\circ}$; es mïssen daher bei den Augen ausser den axial eintretenden Strahlen alle diejenigen in ausgedehntem Masse zur Verwendung kommen, welche von ausserhalb der Axe gelegenen Objekten ausgehend auf die

1) Snellen u. Landolt, die Funktionsprüfungen des Auges. Handb. d. ges. Augenheilk. von Graefe und Saemisch. Bd. III. 1874. p. 58. - A ubert, Physiologische Optik. ibid. Bd. II, cap. IX, p. 592-593. 1876. 